\title{
Practical use of bioenergetic evaluation of sire-bulls with different quality of semen production
}

\author{
Ludmila Samusenko ${ }^{1}$, Andrey Mamaev ${ }^{1}$, Natalya Rodina ${ }^{1}$, and Ekaterina Sergeeva ${ }^{1}$ \\ ${ }^{1}$ Oryol State Agrarian University named after N. V. Parakhin, 302019, Russian Federation, Oryol, Generala Rodina st., 69
}

\begin{abstract}
For modern cattle industry, it is very important to evaluate bull-sires of different breeds by semen quality. The relevance of this problem arises in the context of development of artificial insemination technologies and biotechnology, the increasing role of sire-bulls in the genetic improvement of the herd, which makes it possible to significantly change the breed composition of herds in large regions in a short period of time.

In cattle breeding, sires of Black-and-white and Holstein black-and-white breeds, which are imported into the Russian Federation, are used almost throughout the country.

The purpose of the study is to assess the practical possibility of using the measured data of the bioelectric potential of superficially localized biologically active centres of sire-bulls to evaluate the quality of their semen production.

The subject of the study was the semen production of the bulls of Black-and-white and Holstein blackand-white breeds. The groups were formed according to the principle of analogues; the bulls were from 2 to 4 years old; the body weight was from 700 to $800 \mathrm{~kg}$.

As a result of evaluating the sperm quality in sire-bulls with a high level of biopotential of the superficially localized biologically active centres, in the field of vision of the preparation, spermatozoa with an intact acrosome were found, which amounted to $96.5 \%$ of the total number of spermatozoa of the preparation and had a significant difference with the experimental group. The use of bioenergetic data of the superficially localized biologically active centres makes it possible to evaluate the sperm quality before semen collection and thereby, reduce the time and labour costs for low-quality ejaculates culling.
\end{abstract}

Keywords: bulls, bioelectric potential level, sperm, acrosome, superficially localized biologically active centres.

\section{Introduction}

Evaluation of sire-bulls on the quality of semen production is an important point in the context of industrial dairy farming. The expedience of this issue arose as a result of the active development of biotechnology of artificial insemination and an increase in the importance of sire-bulls in the genetic improvement of the whole population, a breed or individual herds [3, 7].

The semen production collected from sire-bulls must contain a sufficient amount of living sperm cells, which are stable in the external environment and capable of taking part in fertilization.

One of the most common problems in the reproduction of cattle is high content of sperm cells with abnormal acrosome in the ejaculate.

It is known that the acrosome of bull spermia has a less dense consistency than other components of the sperm. Therefore, during sperm storage, degenerative changes occur primarily in the acrosome. The absence and damage of an acrosome in a sperm cell is caused by a violation of the process of spermatogenesis with a genetic determination to this disease.

Acrosome degeneration is expressed in the destruction of the plasma membrane, which leads to a decrease in the fertility of the ejaculate producers. Therefore, early evaluation of the semen quality of sire-bills is an important element of reproduction biotechnology in the context of the development of artificial insemination technologies and the increasing role of sire-bulls in the genetic improvement of herds $[4,5,8]$.

In the light of the active development of the theory of body functional systems, the provision on a single neuroendocrine regulation system, accompanied by the emergence and spread of electrical potentials in living cells and tissues, comes to the fore in solving the problem of evaluating the quality of sperm production. Superficially localized biologically active centres (SLBAC) act as such regulators [12].

In cattle breeding, sire-bulls of Black-and-white and Holstein black-and-white breeds, which are imported into the Russian Federation, are used almost throughout the country [6]. Taking this fact into account, we carried out the study to clarify the inter-breed differences in the quality of semen of the sire-bulls, from which semen banks are created.

The working hypothesis of the current work was the assumption that the spermatogenesis process in sire bulls, closely related to the functional state of the animal organism, affects sperm production, the quantity and 
quality of which can be evaluated by the level of bioelectric potential of superficially localized biologically active centres (LBP SLBAC).

The purpose of the study is to assess the practical possibility of using the measured data of the bioelectric potential of superficially localized biologically active centres of sire-bulls to evaluate the quality of their semen production.

\section{Materials and methods}

The subject of the study was semen production of blackand-white and Holstein bulls. The groups were formed according to the principle of analogues; each group included five animals; the age of the animals was from 2 to 4 years; the body weight was from 700 to $800 \mathrm{~kg}$. The total number of animals was 10 .

The topographic search for SLBACs was carried out according to the method of A. M. Guskov, A. V. Mamaev (1996) using an ELAP-type device [2, 7]. The measurements of the bioelectric potential of SLBACs No. 5 , No. 7 , No. 11 , No. 41 , No. 44 were carried out in the morning, two hours after feeding; its average level was determined. The measurements were carried out throughout the year, by seasons.

Sperm from the bulls was taken in accordance with the semen collection schedule, in compliance with the rules for semen collection. Doublet ejaculates were examined.

The content of sperm cells in ejaculate was studied for anomalous forms using a Hitachi TM -1000 microscope in the preparations made for this purpose according to the technique described in GOST-32277. Sperm acrosomes integrity was evaluated by differential staining.

The obtained data were processed using generally accepted biostatistical methods.

\section{Results}

The use of sire-bulls involves considerable material costs. Before using sire-bulls, a company must be sure that these bulls have breeding value and high reproductive qualities, high degree of cryoresistance and high semen fertilizing ability, that is, it is necessary to determine the reproductive ability and predict the effectiveness of their use.

As a result of the performed measurements (Table 1) of the level of the bioenergetic potential of the SLBAC of the bulls during the experimental period, it was found that in Black-and-white breed the level of the bioenergetic potential of the SLBAC was high and averaged $71.7 \mu \mathrm{A}$, which significantly exceeded similar indicators of sirebulls of the Holstein black-and-white breed by $11.1 \%$ ($\mathrm{p}<0.01)$. Thus, we revealed the dependence of bioenergetic potential level of the SLBAC on the breed.

When analyzing changes in the LBP of centres by seasons, it was found that the highest indicator values were observed in the spring and summer periods in comparison to the winter period in all experimental groups.
Table 1. The dynamics of the biopotential level of superficially localized biologically active centres and the sire-bulls breed, $\mathrm{M} \pm \mathrm{m}$

\begin{tabular}{|c|c|c|}
\hline \multirow[b]{2}{*}{ Indicators } & \multicolumn{2}{|c|}{ Breeds } \\
\hline & $\begin{array}{l}\text { Black-and- } \\
\text { white } \\
\text { (control) }\end{array}$ & $\begin{array}{l}\text { Holstein black- } \\
\text { and-white } \\
\text { (experimental } \\
\text { group) }\end{array}$ \\
\hline $\mathrm{n}$ & 5 & 5 \\
\hline Winter & $66.6 \pm 1.16$ & $57.7 \pm 1,60 * *$ \\
\hline Spring & $75.88 \pm 1.74$ & $63.35 \pm 0,95$ \\
\hline Simmer & $74.38 \pm 1.64$ & $66.76 \pm 1,17$ \\
\hline Autumn & $69.94 \pm 1.37$ & $64.95 \pm 1,05 * *$ \\
\hline Average & $71.7 \pm 1.48$ & $63.19 \pm 0,94 * *$ \\
\hline
\end{tabular}

The differences are statistically significant compared to the control:

$$
* \text { - } \mathrm{p}<0,05 ; * *-\mathrm{p}<0,01 ; * *-\mathrm{p}<0,001
$$

Currently, there is no consensus on the optimal age range of sire-bulls for using their semen production. It is generally accepted that sire-bulls' semen production should be used from the moment bulls reach physiological maturity, that is, starting from 18 months with a body weight of $70 \%$ of that of an adult animal of the corresponding breed. Over the entire period of productive use, it is necessary to accumulate at least 100 thousand doses of semen from a sire-bull, which allows efficient breeding in a population and a breed. An important point in evaluating the reproductive capacity of sire-bulls is determination of the age period of their high sexual potential and, consequently, the quality of semen production.

To identify this period, the studies in which the functional state of sire-bulls was judged by LBP SLBAC were carried out.

As shown by the obtained data (Table 2), the difference in LBP SLBAC of the adult bulls at the age of 4 years old, compared with the young bulls at the age of 2 in the Black-and-white breed is $38.1 \%$; in the Holstein breed, it is $35.4 \%$. Therefore, it can be argued that in 2year-old bulls, the state of homeostasis of the reproductive system does not reach the level of adult animals yet, which is fully consistent with the studies conducted by $\mathrm{Yu}$. N. Baranov (1999) and A. V. Mamaev (2005).

Table 2. The biopotential level of superficially localized biologically active centres and the age of the sire-bulls, $\mathrm{M} \pm \mathrm{m}$

\begin{tabular}{|c|c|c|c|c|}
\hline \multirow{3}{*}{$\begin{array}{c}\text { Indicators } \\
\mathrm{n}\end{array}$} & \multicolumn{4}{|c|}{ Breeds } \\
\hline & \multicolumn{2}{|c|}{ Black-and-white } & \multicolumn{2}{|c|}{$\begin{array}{c}\text { Holstein black-and- } \\
\text { white }\end{array}$} \\
\hline & 5 & 5 & 5 & 5 \\
\hline Age & 2 & 4 & 2 & 4 \\
\hline $\begin{array}{c}\text { No } \\
\text { SLBAC: }\end{array}$ & & & & \\
\hline 5 & $\begin{array}{c}46.6 \pm \\
1.16\end{array}$ & $\begin{array}{c}75.88 \pm 1 \\
74\end{array}$ & $\begin{array}{c}37.7 \pm 1.60 \\
* *\end{array}$ & $\begin{array}{c}63.35 \pm 0 . \\
95\end{array}$ \\
\hline 7 & $\begin{array}{r}44.9 \\
\pm 1.05\end{array}$ & $\begin{array}{r}73.9 \\
\pm 1.61\end{array}$ & $35.3 \pm 1.45$ & $\begin{array}{c}60.4 \pm 0.7 \\
7\end{array}$ \\
\hline 11 & $\begin{array}{c}45.3 \pm \\
1.1\end{array}$ & $\begin{array}{c}72.3 \pm 1.5 \\
1\end{array}$ & $41.7 \pm 1.23$ & $\begin{array}{c}58.6 \pm 0.6 \\
7\end{array}$ \\
\hline
\end{tabular}




\begin{tabular}{|c|c|c|c|c|}
\hline 41 & $\begin{array}{c}45.3 \pm \\
1.2\end{array}$ & $\begin{array}{c}71.3 \pm 1.4 \\
5\end{array}$ & $42.4 \pm 1.3$ & $59.2 \pm 1.7$ \\
\hline 44 & $\begin{array}{c}47.3 \pm \\
1.20\end{array}$ & $\begin{array}{c}77.3 \pm 1.8 \\
3\end{array}$ & $37.5 \pm 1.6$ & $\begin{array}{c}59.7 \pm 0.7 \\
3\end{array}$ \\
\hline $\begin{array}{c}\text { Mean LBP } \\
\text { for 5 }\end{array}$ & $\begin{array}{c}45.88 \\
\pm 1.12\end{array}$ & $\begin{array}{c}74.13 \pm 1 . \\
64\end{array}$ & $\begin{array}{c}38.92 \pm 1.4 \\
3 *\end{array}$ & $\begin{array}{c}60.25 \pm 1 . \\
76 \\
\text { SLBAC }\end{array}$ \\
\hline
\end{tabular}

The differences are statistically significant compared to the control:

$*$ - $\mathrm{p}<0,05 ; * *-\mathrm{p}<0,01 ; * *-\mathrm{p}<0,001$

As a result of the work, we studied the relationship between the quality of sperm and the level of bioenergetic potential of the SLBAC of sire-bulls (Table 3).

Table 3. The quality of sperm and the level of bioenergetic potential of the SLBAC of sire-bulls

\begin{tabular}{|c|c|c|}
\hline Indicators & $\begin{array}{c}\text { LBP SLBAC } \\
\text { high } \\
\text { (control) }\end{array}$ & $\begin{array}{c}\text { LBP SLBAC } \\
\text { low } \\
\text { (experiment) }\end{array}$ \\
\hline $\begin{array}{c}\text { Number of animals } \\
(\mathrm{n})\end{array}$ & 5 & 5 \\
\hline $\begin{array}{c}\text { Mean LBP SLBAC, } \\
\mu \mathrm{A}\end{array}$ & $74.53 \pm 1.33$ & $68.85 \pm 1.32^{* *}$ \\
\hline $\begin{array}{c}\text { Spermatozoa with } \\
\text { intact acrosomes, \% }\end{array}$ & $96.5 \pm 1.85$ & $89.8 \pm 1.67^{*}$ \\
\hline $\begin{array}{c}\text { Spermatozoa } \\
\text { with abnormal } \\
\text { shapes, \% }\end{array}$ & $7.3 \pm 1.53$ & $14.6 \pm 1.49^{*}$ \\
\hline
\end{tabular}

The differences are statistically significant compared to the control:

$*$ - $\mathrm{p}<0,05 ; * *-\mathrm{p}<0,01$;

As it can be seen from the table, the experimental animals were divided according to the biopotential level of their SLBAC into two groups with high LBP SLBAC which is $74.53 \pm 1.33 \mu \mathrm{A}$ and low LBP SLBAC which is $68.85 \pm 1.32 \mu \mathrm{A}(* *-\mathrm{p}<0.01)$.

After evaluating the quality of sperm in sire-bulls with a high level of biopotential of SLBAC, spermatozoa with an intact acrosome were found in the field of view of the preparation, which amounted to $96.5 \%$ of the total number of spermatozoa in the preparation and had a significant difference with the experimental group $(* *-p<0,01)$.

When counting the number of spermatozoa with abnormal forms, the largest number of them was revealed in sire-bulls with a low biopotential level, which amounted to $14.6 \%$ with a significant difference compared to the control.

The study carried out made it possible to establish a direct relationship between LBP SLBAC and the quality of spermatozoa of sire-bulls.

Thus, the use of bioenergetic SLBAC data allows judging the quality of spermatozoa before collecting the semen and, thereby, reduce the time and labour spent on rejection of low quality ejaculates.

\section{References}

1. A.P. Simonenkova, M.V. Yarkina, A.O. Solovyova, A.V. Mamaev, O.N. Luneva Adv. in Eng. Research
Application of Method of Measuring Bioelectric Potential for Evaluation of Milk Fitness in Production of Curd Cheese 151 652(Tyumen, Russian Federation, 2018)

2. A.P. Simonenkova, A.V. Mamaev, V.N. Masalov, O.N. Luneva, E.N. Demina, E.Yu. Sergeeva IOP Conference Series: Earth and Environ. Sci. 640 Evaluation of the quality and safety of butter with an antioxidant complex of natural origin (birch bark extract and Aloe Vera) (Voronezh, Russian Federation, 2020)

3. A.V. Baranov Achiev. of sci. and tech. APC Problems of conservation of biodiversity in animal husbandry 921 (2011)

4. E.V. Chetvertakova Bulletin of the State University The quality of sperm stud bulls of different breeds, depending on the season of the year 8118 (2012)

5. E.S. Gaber Spermatogenesis and its regulation (Nauka, Moscow, 1983)

6. R.N. Lyashuk, A.I. Shendakov Agr. Sci. Results of dairy cattle breeding in the Orel region 720 (2007)

7. M. Mathevon, M.M. Buhr, J.C.M. Dekkers J. of Dairy Sci. Environmental, management and genetic factors affecting semen production in Holstein bulls 813321 (1998)

8. I.I. Sokolovskaya Agr. Biol. Sections of individual structures of the spermatozoid in the process of fertilization IX(5) 746 (1974) 